\title{
A GLYCOSIDE OF MERISTOTROPIC ACID
}

\section{N. P. Kir'yalov and G. S. Amirova}

Khimiya Prirodnykh Soedinenii, Vo1. 4, No. 6, p. 388, 1968

From an extract of the roots of Meristotropis triphylla Fisch. et Mey. we have isolated meristotropic acid [1], the structure $[2,3]$ of which corresponds, probably, to (I). In view of the possibility of the formation in the acid hydrolysis of triterpene compounds of heteroannular dienes, we made an attempt to obtain meristotropic acid or a suitable derivative of it by omitting the stage of acid hydrolysis. An extract of the roots of $\mathrm{M}$. triphylla was boiled with ethanol or methanol. The alcoholic extract was evaporated and cooled. The precipitate that deposited was chromatographed on silica gel. Colorless needle-like crystals with $\mathrm{mp} 208-210^{\circ} \mathrm{C}$ (from ethanol) were obtained.

IR spectrum: 3200 (OH group), 1700 (CO group of a carboxyl), and $1695 \mathrm{~cm}^{-1}$ (CO group of a ketone). UV spectrum: $\lambda_{\max } 258,250$, and $242 \mathrm{~m} \mu$ ( $1.5 \mathrm{mg}$ of substance in $80 \mathrm{ml}$ of $70 \%$ ethanol). It is known that these maxima are also characteristic for meristotropic acid. The substance isolated is perhaps an insufficiently pure glycoside consisting of meristotropic acid and two molecules of uronic acids.

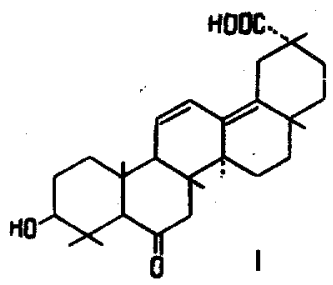

The acid hydrolysis of the glycoside formed meristotropic acid.

The isolation from the roots of $\mathrm{M}$. triphylla of a glycoside with $\mathrm{mp} 208-210^{\circ} \mathrm{C}$ and a characteristic UV spectrum shows that the conjugated system of double bonds in meristotropic acid is created in the plant itself.

\section{REFERENCES}

1. N. P. Kir'yalov and T. N. Naugol'naya, ZhOkh, 33, no. 2, 694, 1963.

2. A. D. Zorina, L. G. Matyukhina, and A. A. Ryabinin, KhPS [Chemistry of Natural Compounds], 2, 217, 1966.

3. N. P. Kir'yalov and G. S. Amirova, KhPS [Chemistry of Natural Compounds], 4, 87, 1968.

13 June 1968

Komarov Botanical Institute, AS USSR

Komarov Botanical Institute, AS AzerbSSR

UDC $547.918+547.597$

\section{A SAPONIN OF PRIMULA TURKESTANICA}

A. M. Zakharov, E. P. Zinkevich, and A. I. Ban'kovskii

Khimiya Prírodnykh Soedinenii, Vol. 4, No. 6, pp. 388-389, 1968

We have studied the subterranean organs of the plant (roots and rhizomes) collected in 1966 in the region of the Chon-Ashu pass (Kirgiz SSR) at a height of $3600 \mathrm{~m}$ above sea level.

From a methanolic extract of the defatted raw material $(1.2 \mathrm{~kg})$, after threefold precipitation with acetone from methanol, we obtained $87 \mathrm{~g}$ of a purified mixture containing about eight compounds.

When this mixture was filtered through inactivated alumina, about $60 \%$ of substances not containing flavonoids was obtained. From the results of chromatography on a thin layer of hydrated silica in the chloroform-methanol-water $(62: 31: 7)$ system, the mixture contained three substances $(A, B$, and $C$ ), of which only A was a saponin. 